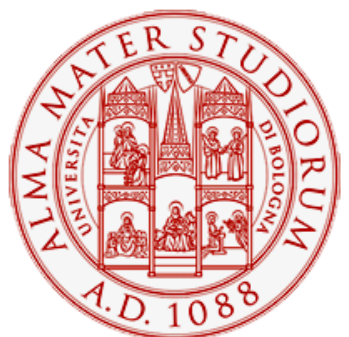

Alma Mater Studiorum - Università di Bologna DEPARTMENT OF ECONOMICS

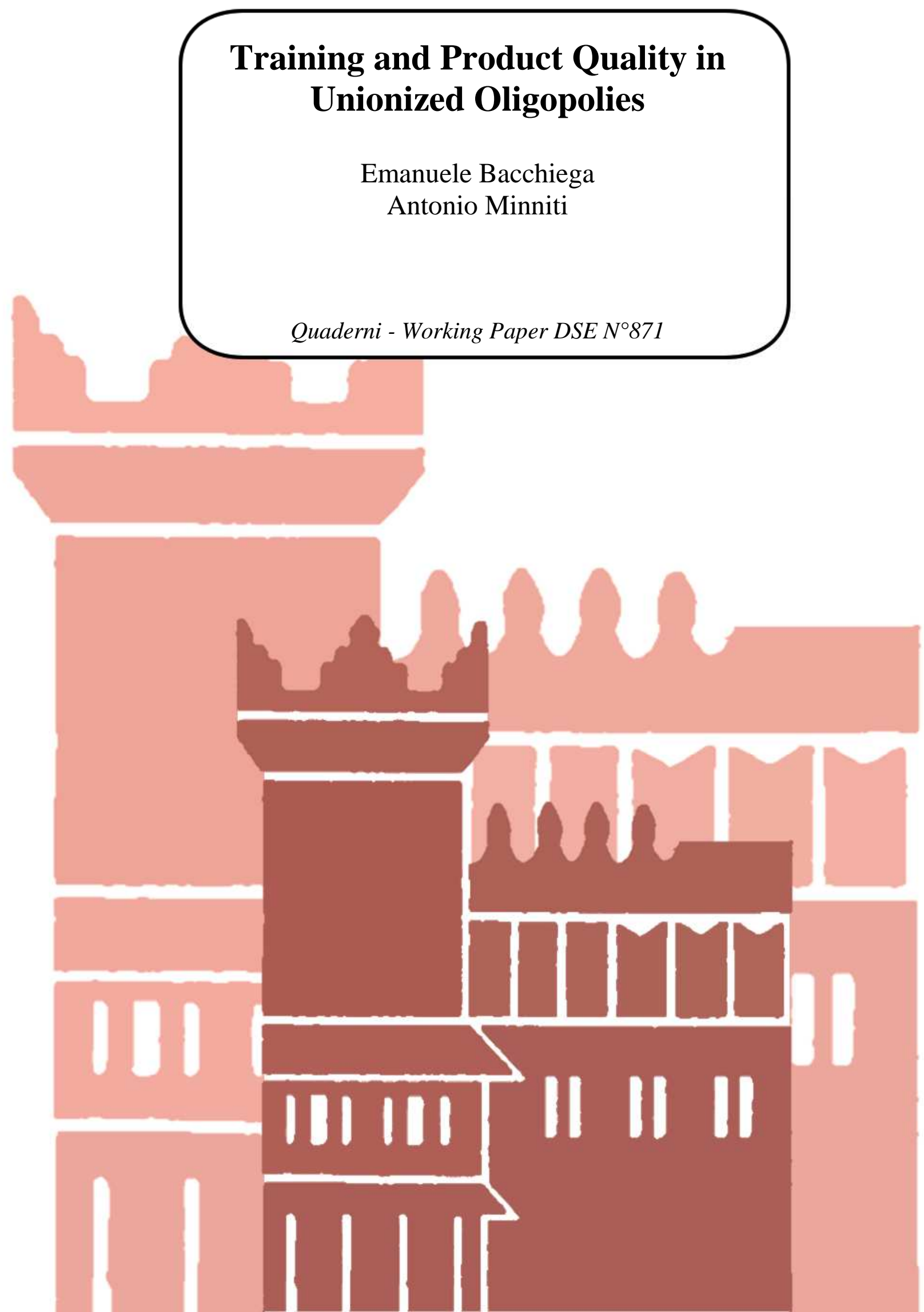




\title{
Training and Product Quality in Unionized Oligopolies
}

\author{
Emanuele Bacchiega* and Antonio Minniti ${ }^{\dagger}$ \\ Dipartimento di Scienze Economiche \\ Alma Mater Studiorum - Università di Bologna, Italy.
}

March 6, 2013

\begin{abstract}
In this paper we analyze the private and public incentives towards skill acquisition when the skill level of workers determines the quality level of goods, and both labor and product markets are non competitive. We delve into the mechanisms that determine the equilibrium skill acquisition outcomes and show that both "pure" (training set by either firms or unions only) and "mixed" (training set by firms and unions) training scenarios may emerge at equilibrium. We show that firms have generally greater training incentives than unions, resulting in a higher product quality. In line with empirical evidence, we also find that the wage differential between high-skill workers and low-skill workers is lower when the training levels of the workforce are selected by unions than by firms. Finally, we analyze the optimal public training skill levels and demonstrate that both unions and firms under-invest in training in comparison with the social optimum. Yet, in this case the skill premium is the lowest.
\end{abstract}

Keywords: Workers' Skills, Product Quality, Unionized Oligopoly, Training.

JEL Codes: L11, L13, J51

\section{Introduction}

Product quality is one of the main dimensions through which firms may gain a competitive edge over their rivals. The empirical literature has emphasized that the extent to which firms can quality-differentiate their products crucially hinges on the availability of quality-differentiated input. Stated differently, there is a quality transfer from input to output. In particular, the role of the skill level of the workforce employed in quality-differentiated industries has been recognized as a key driver of differences in the quality of final products (see Courakis, 1991; Webster, 1993; Maskus et al., 1994; Oulton, 1996; Greenaway and Torstensson, 2000; Martín-Montaner and Ríos, 2002; Schott, 2004 among others).

Despite the empirical relevance of skill availability in determining the performance of an industry with (potentially) quality-differentiated products, little effort has been devoted to a formal analysis of markets where the availability of skilled labor determines the possibility, for oligopolistic firms, of differentiating their products. Relevant exceptions are Gabszewicz and Turrini (1999, 2000). These papers, however, consider the skill level of the workforce to be exogenous. To the best of our knowledge, no paper addresses skill acquisition in a framework where the skill level of the workforce directly determines the quality level of the available products.

The present paper is an attempt to bridge this gap. Indeed, this is a relevant field of investigation, as the skill acquisition decisions of the workforce influence final market competition through the degree of product differentiation. Symmetrically, the extent of market competition determines the revenues of firms, and therefore, the remuneration of inputs and of labor in particular. In such a framework, the existence of skilled labor requirements for the production of a specific variant of a differentiated good provides workers with bargaining power relative to their employers. Consequently, the wage earned by workers does not coincide, in general, with their marginal productivity.

In this paper, we analyze both incentives for skill acquisition and their effects on product market competition when both labor and product markets are not competitive and skill acquisition is costly. ${ }^{1}$ In particular,

\footnotetext{
* $₫$ emanuele.bacchiega@unibo.it

$\dagger$ Corresponding author, $\bowtie$ antonio.minniti@unibo.it

${ }^{1}$ Gabszewicz and Turrini (2000) consider a competitive labour market; thus, the wage rate for skilled workers is determined by the equality of supply and demand of skilled labour. The authors endogenize the decision of whether to acquire skills, but the skill level remains exogenous. In a related paper, Bacchiega (2007) analyzes a non-competitive labor market and considers the Nash bargaining solution to determine the skilled workers' wage. In this paper, however, the process of skill acquisition is exogenous.
} 
we model an industry with two firms and workplace-specific unions. We assume that labor is the only input used in the production process, and each union is the only labor supplier with which a firm is paired. Furthermore, we assume that skills are worthless outside the industry under scrutiny. Accordingly, the remuneration of skilled labor is the result of bargaining between the union representing the workers and the firm that employs the workers. Prior to bargaining over the wage, costly skill acquisition may occur. The skill level of workers determines the quality of the product of the firm that employs them. Different scenarios may emerge according to which agent decides on the skill level to be obtained. In principle, training may be provided by the firm or acquired by the workers themselves. The former case is typically referred to as firm-sponsored training (see, e.g., Booth and Chatterji, 1998; Acemoglu and Pischke, 1998, 1999a,b). The latter case is so-called union-sponsored training (see, e.g., Takahashi and Meléndez, 2004): unions directly engage in workforce-development activities. This second possibility is consistent with the rent-creator role of the union (see Freeman and Medoff, 1979), whereby unions can directly undertake initiatives that increase the productivity of workplace-specific labor. One of these activities is skill creation/enhancement (see Sutherland and Rainbird, 2000; Rigby, 2002 and the references therein). Finally, we consider the case of public training to obtain the socially optimal training levels.

A crucial feature of the present paper is that the training level of the workforce directly influences the degree of market competition through the quality levels of products. An initial, obvious consequence is that, to avoid product homogeneity and a harsh price war, training levels (and consequently product quality) differ. This phenomenon, in turn, has a feedback effect on firm performance and thus on the workers' wages. Regarding competition in the product market, all else being equal, an increase of the quality level of the high-quality good results both in a higher surplus extraction and reduced price competition due to less homogeneous products. However, a quality increase requires costly training. By contrast, a decrease in the quality level of the low-quality good allows for savings in training costs and relaxes price competition but also results in reduced surplus extraction. In the labor market, a higher skill level for the high-skilled workers always increases their wage, whereas the wage of the low-skilled workers increases in their skill level only if product differentiation is sufficiently large. In sum, training has a twofold effect on firms. On the one hand, training may improve firms' market performance through product differentiation. On the other hand, more highly trained workers are paid higher wages, which increases production costs.

For the unions the forces at work are similar. An increase in training always increases the wage of high-skilled workers and may also increase that of low-skilled workers. However, the higher production costs generated by higher wages result in higher prices. This, in turn, reduces the market demands for the two goods and, ultimately, labor demand.

However, there is a relevant difference between the firms and the unions in the incentives for making training investments. The firms control the goods prices, whereas unions do not. This gives firms an additional tool to extract surplus from consumers, and thus it turns out that the returns to training are higher for firms than for unions.

Our main results are as follows. First, the high-skill workers' equilibrium wage is always higher than that of the low-skill workers, reflecting the higher value-added given to the product. Second, we find that the highest skill (and product quality) levels are set in the case where the firms make the training decisions, while the lowest levels are obtained when the unions train the workers. Intuitively, by choosing prices, firms extract more surplus from consumers than unions and, therefore, are able to appropriate higher returns to training. Third, the wage differential between high-skill workers and low-skill workers is lower when the training levels of the workforce are selected by the union than by the firm. This prediction is consistent with empirical evidence on the determinants of the wage mark-up that suggests that unions contribute to reduce wage dispersion within the unionized sectors of the economy (see, e.g., Freeman, 1980, Gosling and Machin, 1994 and Card, 1996). Fourth, we find that mixed training patterns (training provided by one firm and one union) may emerge. In this case, the equilibrium skill levels are intermediate relative to the "pure" cases. Finally, we show that the optimal public training levels are the highest relative to those in all of the "private-training" scenarios, but interestingly, the difference between the skill levels is the least. In this case, market competition is tough and the skill premium is low. The results of the social welfare analysis suggest two general conclusions. First, both unions and firms under-invest in training in comparison with the social optimum. This under-investment problem is due to the fact that by increasing the training levels of the workforce, the quality levels of the products are increased, and thus, the surplus that is generated by consumption. Because both firms and unions do not take into account in their maximization calculations that consumers benefit from higher quality goods, these consumer surplus gains represents the reason why there is under-investment in training from a social perspective. Second, private training leads to larger wage inequality due to higher skill differences. Intuitively, more similar skill levels lead to more homogeneous products, and ultimately to a harsher price war between firms. It follows that tougher competition benefits consumers through lower prices.

Our paper is related to a vast body of work that, departing from traditional human capital theory, has 
called into question the belief that the free market provides adequate incentives to train. This strand of literature argues that, since the markets for training are often characterized by imperfect competition and imperfect information, people generally do not receive adequate compensation for the training they acquire and provide. Within this body of research, Stevens (1994) explores the role of investment externalities due to the imperfect appropriability of transferable training by the firms. In her paper, when firms are imperfect competitors for labour, the benefits from training go not only to employers that provide the training and employees that acquire it but also to firms that poach. The author shows that this "poaching" externality may lead to under-investment in training (see, e.g., Booth and Snower, 1995, Acemoglu, 1997 and Leuven, 2005). We explictly contribute to this literature by showing that, even if training is not transferable, the interaction between product quality and skills may represent another important source of under-provision in training. Our paper is also related to Aidt and Sena (2005) who study the process of skill acquisition in a unionized oligopoly. This paper analyzes the union's choice between the activities of rent extraction and rent creation and considers the degree of market competition as exogenous, whereas in our paper it is endogenously determined by the training decisions. Finally, our paper relates to Oosterbeek et al. (2007) who find that, experimentally, employers have weakly greater incentives for making specific training investments than workers in an outside option bargaining game. Our theoretical analysis confirms this experimental finding. In a recent paper, Shintoyo (2010) develops a search and matching model of general human capital to contrast firm-sponsored training with worker-financed training and evaluate which type of training prevails in the economy. The author shows that firm-sponsored training is more likely to occur when there are greater frictions in the labour market, whereas worker-financed training prevails in a less frictional market. Unlike this paper, we focus on the comparison of the training outcomes in the two different scenarios, rather than determining when one prevails over the other.

The remainder of the paper is organized as follows. Section 2 presents the model. Section 3 determines the possible training equilibria and characterizes them when training is private, while Section 4 addresses optimal public training. Finally, Section 5 provides a brief conclusion.

\section{The Model}

Consider two firms and two unions, and each union is assigned to a firm. All workers are unionized and immobile across unions. Unions are the only suppliers of labor, which is, in turn, the only production factor. We assume that each worker is endowed with one unit of labor that is inelastically supplied. We further assume that one unit of labor is required to produce one unit of a good. Our model is equivalent to one where each firm only hires one worker (see, e.g., Hashimoto, 1981) who supplies the amount of labor required by the firm. Firms may produce vertically differentiated goods depending on the skill level of their workforce. The skill of the workers is fully determined by the amount of training they receive, which is costly and set either by the union the workers belong to or by the firm that hires them. Training is not transferable, so that poaching is not allowed. The workforce's skill level translates into product quality; consequently, a more highly trained worker allows the firm to offer the market a higher quality product. Firms aim at profit

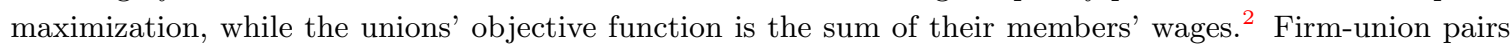
are ex-ante symmetric; however, anticipating an equilibrium argument, we shall assume that one of them provides the workers with more training than the other. Accordingly, we will label the former "high-skill workers" and the latter "low-skill workers". The reason for this approach is that if both train the workers to the same skill level, the quality of the goods produced by the firms would be the same, making the good produced by the two firms homogeneous. This outcome, combined with price competition, would result in a profit-dissipating price war. ${ }^{3}$ Let $s_{h}$ be the skill level of the high-skilled workers and $s_{l}$ that of the low-skilled workers, with $s_{h}>s_{l}$. We assume that the skill level of the workforce determines the quality of the product; accordingly, $s_{i}, i=h, l$ also represent the objective quality levels of the goods. This entails that one firm produces the high- and the other the low-quality product. We will label the first firm "firm $h$ " and the second "firm $l$ ". 4

On the consumption side, we will assume that there is a unit-mass continuum of consumers that are heterogeneous with respect to quality appreciation. Label this quality appreciation $\theta$ and let $\theta \in[0, \bar{\theta}]$. They purchase at most one unit of the good. The utility consumers derive from consumption is standardly defined

\footnotetext{
${ }^{2}$ The present model, therefore, belongs to the class of Right-to-Manage oligopolized union models; see, e.g., McDonald and Solow (1981) or Nickell and Andrews (1983), and for a recent survey on unionized oligopolies, Goeddeke (2010).

${ }^{3}$ Alternatively, one could imagine that the training level defines the maximal attainable product quality, and that each firm then selects an actual quality no greater than that. In this case as well, however, each firm-union pair selects different quality levels to avoid the Bertrand paradox. It is clear that any skill level "in excess" of that strictly necessary to produce the desired quality is a waste of resources.

${ }^{4}$ Summarizing, the quality levels are determined by the skill of the workforce and thus by the training choices of firms and/or unions.
} 
à la Mussa and Rosen (1978), so that their surplus is:

$$
U(\theta)= \begin{cases}\theta s_{i}-p_{i} & \text { if buying one unit of good } i, \\ 0 & \text { if abstaining from consumption. }\end{cases}
$$

In (1) $u_{i}(i=h, l)$ is the quality of good $i$, and $p_{i}$ is its market price. Demands for the high- and low-quality goods are easily derived through the marginal consumer approach. Label them $D_{h}$ and $D_{l}$ :

$$
D_{h}=\frac{1}{\bar{\theta}}\left(\bar{\theta}-\theta_{h l}\right), \quad D_{l}=\frac{1}{\bar{\theta}}\left(\theta_{h l}-\theta_{l 0}\right),
$$

where $\theta_{h l}=\frac{p_{h}-p_{l}}{s_{h}-s_{l}}$ identifies the consumer indifferent between buying one unit of the high-quality good or one unit of low-quality good, and $\theta_{l 0}=p_{l} / s_{l}$ is that indifferent between low-quality consumption and abstaining from consumption altogether. The profits of the high- and low-quality firms, gross of training costs, are therefore:

$$
\pi_{h}=D_{h}\left(p_{h}-w\right), \quad \pi_{l}=D_{l}\left(p_{l}-r\right),
$$

where $w$ and $r$ are the wages paid to the high-skilled and low-skilled workers, respectively, which are determined by the bargaining taking place within each firm-union pair.

For the sake of clarity, we will refer to the union of the high-skilled workers as the "high-skill union" and to the other as the "low-skill union". Each union comprises the same number of workers, which we assume to be greater than one. ${ }^{5}$ The unions' objective functions (gross of training costs) are as follows (see, e.g., Sørensen, 1992):

$$
E_{h}=D_{h} w \quad E_{l}=D_{l} r .
$$

The wages of the high- and low-skilled workers are determined by bargaining that takes place within each firm-union pair. We use the Nash Bargaining solution to obtain the bargaining outcome (see, e.g., Naylor, 1998, 1999, 2000 and the references therein).

We conclude the structure of the model by describing the costs of training the workforce. Training generates a cost that is increasing and convex in the skill level itself. To be more concrete, to train the workers from their initial skill level (which we normalize to 0) to, say, $\bar{s}$, $\operatorname{costs} C(\bar{s})=\bar{s}^{2} / 2$. What we have in mind with this formulation is a situation where improving the skill level of the workforce hinges on fixed costs, and hence to train a worker more generates a negligible additional cost.

The interaction among firms and unions unfolds as follows. At the first stage, either the firms or the unions decide on the amount of training provided to workers. At the second stage, bargaining over the workers' wage takes place within each firm-union pair. At the third stage, firms set prices and employment is therefore determined. Actions within each firm-union pair and between them are simultaneous at each stage. We solve the game through backward induction to obtain subgame-perfect Nash equilibria.

\section{Equilibrium}

\subsection{Pricing stage}

In the last stage, firms simultaneously set prices. Standard maximization techniques lead to the following optimal prices:

$$
\hat{p}_{h}=\frac{s_{h}\left[2 \bar{\theta}\left(s_{h}-s_{l}\right)+r+2 w\right]}{4 s_{h}-s_{l}}, \quad \hat{p}_{l}=\frac{\bar{\theta} s_{l}\left[\left(s_{h}-s_{l}\right)+w\right]+2 r s_{h}}{4 s_{h}-s_{l}} .
$$

Second order conditions are fulfilled so long as $s_{h}>s_{l}$. By plugging (5) back into (2), (3) and (4) we obtain:

$$
\begin{aligned}
\hat{D}_{h}=\frac{2 \bar{\theta} s_{h}\left(s_{h}-s_{l}\right)-s_{h}(2 w-r)+w s_{l}}{\bar{\theta}\left(4 s_{h}-s_{l}\right)\left(s_{h}-s_{l}\right)}, & \hat{D}_{l}=\frac{s_{h}\left[\bar{\theta} s_{l}\left(s_{h}-s_{l}\right)+(w+r) s_{l}-2 r s_{h}\right]}{\bar{\theta} s_{l}\left(s_{h}-s_{l}\right)\left(4 s_{h}-s_{l}\right)} ; \\
\hat{\pi}_{h}=\hat{D}_{h}^{2} \bar{\theta}\left(s_{h}-s_{l}\right), & \hat{\pi}_{l}=\hat{D}_{l}^{2} \bar{\theta}\left(s_{h}-s_{l}\right) \frac{s_{l}}{s_{h}}
\end{aligned}
$$

and

$$
\hat{E}_{h}=\hat{D}_{h} w, \quad \hat{E}_{l}=\hat{D}_{l} r
$$

\footnotetext{
${ }^{5}$ This assumption is sufficient to avoid rationing issues in the model, as even if all the consumers only patronized a single firm, labor would be sufficient to satisfy the demand. Rationing in models of vertical differentiation raises several issues, see Boccard and Wauthy 2010.
} 


\subsection{Wage bargaining}

The wages of the high- and low-skilled workers are determined through symmetric Nash bargaining between the firm and the union within each firm-union pair. The profit is the objective function for the firms and the total wages earned by the workers is that of the union (see, e.g., Sørensen, 1992). We assume that if no agreement is reached, the firm cannot produce any of the good, thus the outside option for the firms is zero. We also normalize the union's outside option to zero. Accordingly, the problems determining the wages of the high- and low-skilled workers are, respectively:

$$
\max _{w} \hat{E}_{h} \hat{\pi}_{h}, \quad \max _{r} \hat{E}_{l} \hat{\pi}_{l} .
$$

The problems defined in (9) assume that the bargaining power of firms and unions is the same. This keeps the model tractable and yields analytical results for all the model variables. Numerical exercises, however, reveal that the use of the weighted Nash product, with weights that may differ across firm-union pairs, leaves our results qualitatively unchanged for a relevant parameter constellation. ${ }^{6}$

The solutions to the problems in (9) are:

$$
\hat{w}=\frac{s_{h}\left[2 \bar{\theta}\left(s_{h}-s_{l}\right)+\hat{r}\right]}{4\left(2 s_{h}-s_{l}\right)}, \quad \hat{r}=\frac{s_{l}\left[\bar{\theta}\left(s_{h}-s_{l}\right)+\hat{w}\right]}{4\left(2 s_{h}-s_{l}\right)} .
$$

The solution to the system defined by (10) is easy to obtain:

$$
w^{*}=\frac{\bar{\theta} s_{h}\left(16 s_{h}-7 s_{l}\right)\left(s_{h}-s_{l}\right)}{64 s_{h}^{2}-65 s_{h} s_{l}+16 s_{l}^{2}}, \quad r^{*}=\frac{2 \bar{\theta} s_{l}\left(5 s_{h}-2 s_{l}\right)\left(s_{h}-s_{l}\right)}{64 s_{h}^{2}-65 s_{h} s_{l}+16 s_{l}^{2}} .
$$

An inspection of (11) allows us to state the following:

Lemma 1. $w^{*}>r^{*}$ for all $s_{h}>s_{l}$.

At equilibrium, the high-skilled workers receive a higher wage than the low-skilled workers. It is worth noting that the skill premium does not originate from a greater productivity among high-skilled workers, as the physical productivities of high- and low-skilled labor are the same. It also does not emerge from greater bargaining power on the part of the high-skilled union. ${ }^{7}$ Rather, the skill premium stems from the value in terms of quality that the skilled workers add to the good.

Substituting (11) back into (7) and (8) yields:

$$
\pi_{h}^{*}=\frac{9\left(w^{*}\right)^{2}\left(2 s_{h}-s_{l}\right)^{2}}{\zeta\left(4 s_{h}-s_{l}\right)}, \quad \pi_{l}^{*}=\frac{9\left(r^{*}\right)^{2} s_{h}\left(2 s_{h}-s_{l}\right)^{2}}{\zeta s_{l}\left(4 s_{h}-s_{l}\right)},
$$

and

$$
E_{h}^{*}=\frac{3\left(w^{*}\right)^{2}\left(2 s_{h}-s_{l}\right)}{\zeta} \quad E_{l}^{*}=\frac{3\left(r^{*}\right)^{2} s_{h}\left(2 s_{h}^{2}-3_{h} s_{l}+s_{l}^{2}\right)^{2}}{\zeta s_{l}\left(s_{h}-s_{l}\right)}
$$

where $\zeta \equiv \bar{\theta}\left(4 s_{h}-s_{l}\right)\left(s_{h}-s_{l}\right)$.

\subsection{Training}

We are now in a position to address the training stage of our model. As mentioned previously, training in our case takes the form of a fixed cost that is paid to increase the skill level of the workers from the initial level (normalized to zero) to the desired one. The skill level of the workforce defines the quality level of the good produced by the firm. Four alternative scenarios will be analyzed depending on who makes the training investment decision. Training may be set by firms alone, by unions alone, or by one union and one firm, and in this case either may be the actor electing to train to the high-skill level the workforce. In our setting, explicit cost sharing is not possible as in MacLeod and Malcomson (1993). Rather, it is assumed that the actor who takes the decision of how much to invest in training bears the full costs of it. We begin with the case where the firms set the training levels of their workforce; for the convenience of the reader, we will label this case " $f$ ". The profit functions of the firms are:

$$
\pi_{h}^{*}-C\left(s_{h}\right), \quad \pi_{l}^{*}-C\left(s_{l}\right)
$$

Firms simultaneously and non-cooperatively maximize profits as in (14). We can state the following.

\footnotetext{
${ }^{6}$ See Appendix E for some numerical examples of asymmetric bargaining.

${ }^{7}$ It can be demonstrated that, even if bargaining powers differ within each firm-union pair, the result that high-skilled workers earn a higher wage than low-skilled workers may be robust to the situation where the low-skilled union has greater relative bargaining power than the high-skilled union. The proof is available upon request.
} 
Lemma 2. The skill (and quality) levels chosen by the firms at the unique subgame-perfect Nash equilibrium are $s_{h}^{f}=0.1453 \bar{\theta}$ and $s_{l}^{f}=0.0416 \bar{\theta}$. The profits and total wages are $\pi_{h}^{f}=0.0073 \bar{\theta}^{2}, \pi_{l}^{f}=0.0012 \bar{\theta}^{2}$; $E_{h}^{f}=0.0129 \bar{\theta}^{2}$ and $E_{l}^{f}=0.0015 \bar{\theta}^{2}$. The wages paid to workers are $w^{f}=0.031 \bar{\theta}^{2}$ and $r^{f}=0.0056 \bar{\theta}^{2}$ and the equilibrium prices are $p_{h}^{f}=0.0741$ and $p_{l}^{f}=0.0134$.

Proof. See Appendix A.

Now consider the case where the unions decide the training level of the workers, and label it case " $u$ ". The unions simultaneously and non-cooperatively set the workers' training levels to maximize their objective functions:

$$
E_{h}^{*}-C\left(s_{h}\right), \quad E_{l}^{*}-C\left(s_{l}\right)
$$

We state

Lemma 3. The skill (and quality) levels chosen by the unions at the unique subgame-perfect Nash equilibrium are $s_{h}^{u}=0.0983 \bar{\theta}$ and $s_{l}^{u}=0.032 \bar{\theta}$. The profits and total wages are $\pi_{h}^{u}=0.0117 \bar{\theta}^{2}, \pi_{l}^{u}=0.0015 \bar{\theta}^{2}$; $E_{h}^{u}=0.0038 \bar{\theta}^{2}$ and $E_{l}^{u}=0.0006 \bar{\theta}^{2}$. The wages paid to workers are $w^{u}=0.0204 \bar{\theta}^{2}$ and $r^{u}=0.0042 \bar{\theta}^{2}$ and the equilibrium prices are $p_{h}^{u}=0.0483$ and $p_{l}^{u}=0.01$.

Proof. See Appendix B.

Lemmas 2 and 3 describe the possible outcomes of the training decisions. To understand the mechanisms behind them, it is worth determining the basic forces at work. By training their workers, the firms or unions increase their skill level, which directly translates to increased quality in the good produced by the firm. This affects the consumers' willingness to pay for the product and, consequently, the surplus that can be extracted. Note, however, that this outcome also affects product market competition, as the goods are vertically differentiated, and price competition depends on the degree of product differentiation. Consequently, each "trainer" faces a trade-off. For the agent training the workforce to the high-skill level, an increase in training generates higher training costs, but all else being equal, an increase in the consumer surplus that can be extracted and a reduction in competition due to less homogeneous products. A reduction in training, however, allows for cost savings but fosters competition because of more homogeneous products. The reasoning is specular for the agent setting the low-skill training level. An increase in training, all else being equal, increases training costs and makes the products more homogeneous but also makes consumers more willing to pay for the good, while a reduction in training reduces costs and competition but also reduces the surplus that can be extracted from consumers.

Furthermore, firms and unions have specific incentives regarding training. Firms pay their workers an individual wage that is a function of their training levels. In particular, the wage of the high-skilled workers is always increasing in their skill level, thus the marginal production cost of the high-quality firm increases in the skill level of its workforce, which reduces further the firm's incentives to train its workers. A similar argument applies to the effect of an increase in training among the low-skilled workers on their wage. This wage is increasing for all $0<s_{l} / s_{h}<0.6537$; it then decreases because of the decline in gross profits due to product homogeneity. It is easy to ascertain that at all the equilibria described in the preceding Lemmata, the ratio of the training levels lies within that interval. In other words, for the low-quality firm, an increase in the training level of its workforce also increases the marginal production cost. Regarding the unions, an increase in the skill level of their members increases the wages they earn but, simultaneously, increases the price of the good they are employed to produce, due to the increase in the marginal cost, hence reducing its demand and the number of workers effectively employed.

These observations are useful in understanding the results of Lemmas 2 and 3. The highest possible training (and quality) levels are set when the firms make the training decision. As noted above, an increase in the training level triggers a twofold increase in their costs. First, directly due to the cost of training $C(\cdot)$, and second, it indirectly increases the marginal production cost because of the higher wage paid to the workers. Nonetheless, the high-quality firm recoups these costs by increasing the consumers' willingness to pay for the good through an increase in the quality of the good and accordingly setting a high price for the good itself. This relaxes price competition, and the low-quality firm can therefore also set a high training level and extract additional surplus from consumers through higher quality and a high price.

The opposite case is obtained when the unions make the training decision. In this case, in addition to the direct cost of training $C(\cdot)$, the increase in the wage has a positive effect on the objective function of the union, but also has a negative one through the reduction in demand following an increase in the marginal production cost of the firm. Unlike the firms, however, the unions cannot use the price to directly extract surplus from consumers. This ultimately reduces their incentives to train workers.

As a final remark, let us expand on the individual wages $w$ and $r$ paid to workers and the wage mark-up. In general, the presence of a training-setting firm increases the wage paid to the workers. This phenomenon can be easily ascertained by an inspection of the wages reported in Lemmas 2 and 3. The intuition for 
this is to be found in the higher training level selected by firms which translates to higher product quality and ultimately in value-added to the product. Let us now turn to the wage mark-up. From Lemma 2 and Lemma 3 it easily follows that the wage differential between workers with different skills is lower when the training levels of the workforce are selected by the union than by the firm. This result is in accordance with several studies on the wage mark-up for different skill groups that indicate that unions contribute to reduce wage dispersion within the unionized sectors of the economy (see, e.g., Freeman 1980). ${ }^{8}$

To conclude the analysis, we will consider the last two "mixed" cases where in one pair the firm sets the training level and the union does in the other. In this case, let the apex identify the agent setting the high and low training level, respectively. ${ }^{9}$

Lemma 4. (i) There exists a unique subgame-perfect equilibrium where in one pair the union selects the high level of training and in the other pair the firm selects the low level of training. At this equilibrium, the training levels are $s_{h}^{u f}=0.0997 \bar{\theta}$ and $s_{l}^{u f}=0.0359 \bar{\theta}$. The profits and total wages are $\pi_{h}^{u f}=0.0116 \bar{\theta}^{2}, \pi_{l}^{u f}=0.001 \bar{\theta}^{2} ; E_{h}^{u f}=0.0036 \bar{\theta}^{2}$ and $E_{l}^{u f}=0.0012 \bar{\theta}^{2}$. The wages paid to workers are $w^{u f}=0.0201 \bar{\theta}^{2}$ and $r^{u f}=0.0046 \bar{\theta}^{2}$ and the equilibrium prices are $p_{h}^{u f}=0.0474$ and $p_{l}^{u f}=0.0108$.

(ii) There exists a unique subgame-perfect equilibrium where the in one pair the firm selects the high level of training and in the other pair the union selects the low level of training. At this equilibrium, the training levels are $s_{h}^{f u}=0.1437 \bar{\theta}$ and $s_{l}^{f u}=0.0343 \bar{\theta}$. The profits and total wages are $\pi_{h}^{f u}=0.0078 \bar{\theta}^{2}$, $\pi_{l}^{f u}=0.0017 \bar{\theta}^{2} ; E_{h}^{f u}=0.0013 \bar{\theta}^{2}$ and $E_{l}^{f u}=0.0006 \bar{\theta}^{2}$. The wages paid to workers are $w^{f u}=0.0317 \bar{\theta}^{2}$ and $r^{f u}=0.0048 \bar{\theta}^{2}$ and the equilibrium prices are $p_{h}^{f u}=0.0763$ and $p_{l}^{f u}=0.0115$.

Proof. See Appendix C.

The previous discussion is helpful in understanding the results reported in Lemma 4, consider part $(i)$ of the Lemma first. In the firm-union pair producing the high-quality good, the union sets the training level, while in the other pair, the low-level of training is selected by the firm. Recall that the union has less incentive to make training investments than the firm because it cannot set the final price, which explains the reduced level of training provided to high-skilled workers with respect to the case where the two firms make the training decision (case $f$ ). In contrast, the low-quality firm can appropriate consumer surplus through both training and price setting, which fosters its incentives to provide training. This result yields a training (and quality) level that is larger than that obtained in the case where training levels were set by the two unions (case $u$ ). A similar rationale applies, specularly, to part (ii) of the Lemma. In this case, a high level of training is selected by the firm, whereas the low-level is selected by the union. The union has "low" training incentives, therefore it sets a training level below that in the two-firm case $f$. In contrast, the firm can also set the market price; hence it invests more than in the two-union case $u$. However, the training and quality levels selected by the firm are lower than in the two-firm case, which may be explained by referring to strategic interaction. In this case, the firm knows that the union will limit its investment in (low-level) training, which will result in a "low" product quality level. Consequently, the training investment required for the firm to achieve an optimal product differentiation level is lower, allowing the firm to save on training costs.

We will summarize the results of the previous Lemmas in the following

Proposition 1. The highest workers' skill and product quality levels are obtained in case $f$, whereas the lowest are obtained in case $u$. Cases uf and $f u$ entail intermediate training and quality levels.

Proof. Follows from direct comparison.

Our discussion highlights that the training decisions determine the remuneration of workers and contribute to shaping competition in the product market. Consequently, they also have effects on consumer surplus and total welfare. We address issue of the welfare effects of training in the following section.

\section{Public training and Welfare}

In this section, we explore the case where the training levels of the workers are determined by a benevolent social planner. The relevance of the public policies aimed to foster skill acquisition and a clear understanding

\footnotetext{
${ }^{8}$ Freeman (1984), analyzing longitudinal data, confirms the finding of lower wage inequality in the union sector. In particular, Freeman documents that wage dispersion tends to fall when workers leave nonunion for union jobs and to rise when they move in the opposite direction. Freeman (1991), using more recent longitudinal data, confirm that unionization reduces wage inequality. The author finds that declining unionization accounts for about 20 percent of the increase in the standard deviation of male wages in the U.S. between 1978 and 1988. More recently, a similar conclusion is also reached by Gosling and Machin (1994) and Card (1996).

${ }^{9}$ As an example, $s_{l}^{u f}$ is the training level of the low-skilled workers when the union $(u)$ sets the high training level in one pair and the firm $(f)$ sets the low training level in the other.
} 
of the mechanisms that drive it, is stressed, for example, in OECD (2011). In line with the preceding analysis, we will adopt a partial-equilibrium perspective here. Thus, as is standard in this approach, we define the welfare of the industry as the sum of consumer surplus, firm profits and total wages minus training costs, formally:

$$
\begin{array}{r}
W\left(s_{h}, s_{l}, \bar{\theta}\right)= \\
=\frac{1}{\bar{\theta}}\left[\int_{\theta_{l 0}}^{\theta_{h l}}\left(\theta s_{l}-p_{l}\right) d \theta+\int_{\theta_{h l}}^{\bar{\theta}}\left(\theta s_{h}-p_{h}\right) d \theta\right]+\pi_{h}+\pi_{l}+E_{h}+E_{l}-C\left(s_{h}\right)-C\left(s_{l}\right)= \\
=\frac{1}{\bar{\theta}}\left(\int_{\theta_{l 0}}^{\theta_{h l}} \theta s_{l} d \theta+\int_{\theta_{h l}}^{\bar{\theta}} \theta s_{h} d \theta\right)-C\left(s_{h}\right)-C\left(s_{l}\right) .
\end{array}
$$

We assume that a benevolent social planner may set the skill levels of the workforce by taking oligopoly pricing as given. Furthermore, the social planner cannot (directly) modify the number of competing firms or unions, nor it can change the balance of bargaining power between them. ${ }^{10}$ Moreover, we assume that the training cost of the social planner is equal to that of the firms and unions and therefore rule out the possibility that public training is more efficient than its private counterpart. The planner's optimization problem is therefore:

$$
\max _{s_{h}, s_{l}} W\left(s_{h}, s_{l}, \bar{\theta}\right)
$$

and the following lemma provides its solution.

Lemma 5. The socially optimal training (and quality) levels are $u_{h}^{W}=0.3056 \bar{\theta}$ and $s_{l}^{W}=0.2077 \bar{\theta}$.

Proof. See Appendix D.

The socially optimal training levels have two relevant features relative to those set by firms and/or unions. First, their absolute values are the highest among all the possible training levels and, second, their relative difference is the lowest. The reason that the social planner increases the level of training is related to the increased quality generated by increased skills. By increasing the training levels of the workforce, the quality levels of the products are increased, and thus, the surplus that is generated by consumption. Because both firms and unions do not take into account in their maximization calculations that consumers benefit from higher quality goods, these consumer surplus gains lead to under-investment in training. The reason that the social planner reduces the skill differences is also related to the product market effects of training. More similar skill levels lead to more homogeneous products, and ultimately to a harsher price war between firms, which results in lower prices. On the one hand, this increases the surplus consumers enjoy; on the other hand, it increases the total demand for the two products. It is simple to determine that the equilibrium prices corrected for quality $\left(p_{i} / u_{i}\right)$ under the socially optimal training levels are the lowest among all possible scenarios, while the equilibrium demands are the highest. ${ }^{11}$

\section{Discussion and Conclusion}

In this paper, we analyzed the private and public incentives to train workers when their skill determines product quality and both product and labor markets are imperfectly competitive. We have demonstrated that both "pure" training scenarios (training levels are set by either firms or unions) and "mixed" ones (training simultaneously set by firms and unions) may emerge. Furthermore, in all scenarios, firms have greater incentives to engage in training than unions; consequently, the skill levels they set are generally higher, resulting in higher product quality. Finally, we analyzed the optimal public training levels and found that, the skill levels provided are higher in this case, resulting in high average quality in the market.

Let us put now our paper into perspective. Our analysis was conducted under the assumption of symmetric Nash Bargaining. A natural question that may arise concerns the effect of different bargaining weights in the bargaining process. Unfortunately, a model featuring a generalized Nash Bargaining solution is not tractable. However, some insights on the characteristics of such a model can be drawn using numerical exercises performed by allowing the relative weights in the bargaining process change. In particular, tables 1-4 in Appendix E report the equilibrium values for the model's variables under the assumptions of all bargaining power going to the workers (monopoly union), $75 \%$ of the bargaining power going to the workers

\footnotetext{
${ }^{10}$ This is a second-best optimum.

${ }^{11}$ Our modeling of the public training process implicitly assumes that the skill levels of workers still completely determines the quality levels of the products. Stated differently, firms can neither ask their workers to only partially use their skills to reduce the quality level of the final commodity, nor can they provide additional training to increase the quality level of the good with the aim of reducing price competition. One possible justification for this assumption is that, as we do not consider asymmetric information issues, the planner is able to verify the quality level of the final product and sanction the firms that under- or over-provide quality with respect to the socially optimal level.
} 
and $25 \%$ to the firms, the symmetric case of $75 \%$ to the workers and $25 \%$ to the firms and finally the case of all bargaining power going to the firms. As a general, unsurprising remark, it is worth noting that an increase in the bargaining power of an agent increases its payoff, and that, from a social welfare perspective, any positive bargaining power to the workers reduces the aggregate welfare because it increases marginal production costs. Additional interesting intuitions are conveyed by an analysis of the optimal skill (and quality) levels. First, an inspection of the optimal training levels reveals that an increase (decrease) in the bargaining power of the agent setting the training level results in an increase (decrease) in the amount of training provided. This is intuitive. An increase (decrease) in the bargaining power increases (decreases) the appropriability of the returns on the investments in skills, and therefore raises (dampens) the incentives to invest in training. Second, it is instructive that even in the case of asymmetric bargaining power, the firms have greater incentives for providing training than the unions. Compare, for instance, the equilibrium skill levels set by the unions when they have $75 \%$ of the bargaining power (column $u$ of table 2) with those set by the firms in the symmetric case (column $f$ of table 3 ). This confirms the intuition obtained for the symmetric bargaining case. Firms set prices, which gives them a direct tool to extract consumer surplus. Thus, they have greater incentives than unions to invest in training, as the resulting higher quality increases the willingness to pay for the goods. Third, in the case of asymmetric bargaining powers, some training configurations may not be a subgame-perfect Nash equilibrium of the game. In particular, when the workers have "most of" the bargaining power, no mixed-configuration with one firm training to the high-skill level and one union training to the low-skill level exists. In this case, the union has incentives to deviate and "leapfrog upwards" to provide a high skill level. This outcome originates from the fact that, in general, higher profits and higher total wages are earned by the pair producing the high-quality good. When unions are stronger than firms at the bargaining stage, the "high-skill" training level set by a firm is low because it has low bargaining power (see the above discussion). Consequently, for the union, the increase in training required to surpass this training level -and, thus, to reap a higher total wage- is "low". A similar reasoning applies for the case where the firms have greater bargaining power than the unions. The most relevant difference between the two cases is that when all of the bargaining power is held by the firms, no equilibrium exists with at least one union setting the quality level (see table 4). The intuition for this result is straightforward. When all of the bargaining power is held by the firms, the wage paid to the workers is equal to the outside option, which does not depend on the quality level of the good. This phenomenon makes any investment in training non-appropriable by the unions and ultimately entails that no union is willing to provide training. Finally, it is worth noting that in the polar case where all of the bargaining power is held by the unions, the firms still have positive incentives to invest in training. Again, this outcome occurs because the firms set prices, and, therefore, may impose a wedge between the bargained wage (their average production cost) and the price.

\section{Appendices}

\section{A Proof of Lemma 2}

We follow the approach developed by Motta (1993). The first-order conditions with respect to the quality levels are as follows. ${ }^{12}$

$$
\begin{gathered}
\frac{\partial\left[\pi_{h}^{*}-C\left(s_{h}\right)\right]}{\partial s_{h}}=0 \quad \Leftrightarrow \quad\left(16 s_{h}-7 s_{l}\right) \phi \gamma=s_{h}, \\
\frac{\partial\left[\pi_{l}^{*}-C\left(s_{l}\right)\right]}{\partial s_{l}}=0 \quad \Leftrightarrow \quad 4 s_{h}\left(3 s_{h}-s_{l}\right) \psi \gamma=s_{l},
\end{gathered}
$$

where $\phi \equiv\left(8192 s_{h}^{6}-23424 s_{h}^{5} s_{l}+30360 s_{h}^{4} s_{l}^{2}-22270 s_{h}^{3} s_{l}^{3}+9579 s_{h}^{2} s_{l}^{4}-2256 s_{h} s_{l}^{5}+224 s_{l}^{6}\right), \psi \equiv\left(2560 s_{h}^{5}+\right.$ $\left.-8792 s_{h}^{4} s_{l}+10822 s_{h}^{3} s_{l}^{2}-6307 s_{h}^{2} s_{l}^{3}+1778 s_{h} s_{l}^{4}-196 s_{l}^{5}\right)$ and $\gamma \equiv \frac{9 \bar{\theta} s_{h}\left(2 s_{h}-s_{l}\right)}{\left(4 s_{h}-s_{l}\right)\left(64 s_{h}^{2}-65 s_{h} s_{l}+16 s_{l}^{2}\right)^{3}}$. By allowing $s_{h}=\alpha s_{l}$, with $\alpha>1$, dividing (20) by (21) and rearranging terms we obtain

$$
\frac{-51200 \alpha^{8}+327392 \alpha^{7}-718904 \alpha^{6}+862444 \alpha^{5}-654856 \alpha^{4}+327298 \alpha^{3}-104717 \alpha^{2}+19376 \alpha-1568}{51200 \alpha^{7}-196320 \alpha^{6}+286776 \alpha^{5}-212716 \alpha^{4}+86016 \alpha^{3}-18144 \alpha^{2}+1568 \alpha}=0 .
$$

The only solution of (22) larger than one is $\alpha=3.496$. By plugging this value back into the first-order condition, we obtain $s_{h}^{f}=0.1453 \bar{\theta}$ and $s_{l}^{f}=0.0416 \bar{\theta}$. To complete the proof that these values are indeed part of the equilibrium strategies of the game, we need to ascertain that no firm has an incentive to "leapfrog"

\footnotetext{
${ }^{12}$ Global concavity for firm $h$ is satisfied for all $s_{h}>s_{l}$, while for firm $l$ it can be demonstrated that local concavity at the optimal training levels is fulfilled.
} 
the rival. We begin by confirming the absence of such a deviation for the low-quality firm. If this firm "leapfrogs" its rival, it sets a training level for the workforce equal to $s_{l}^{D f}>s_{h}^{f}$, earning thus a profit equal to

$$
\pi_{l}^{D}\left(s_{h}^{f}, s_{l}^{D f}\right)=\frac{1}{2} s_{h}^{2}\left[\frac{18 \bar{\theta}\left(s_{h}-0.1453 \bar{\theta}\right)\left(32 s_{h}^{2}-4.3588 \bar{\theta} s_{h}+0.1478 \bar{\theta}^{2}\right)^{2}}{\left(256 s_{h}^{3}-47.0753 \bar{\theta} s_{h}^{2}+2.7232 \bar{\theta}^{2} s_{h}-0.0491 \bar{\theta}^{3}\right)^{2}}-1\right] .
$$

It may be determined that (23) is negative for all $s_{l}^{D f}>s_{h}^{f}$ and $\bar{\theta}>0$. We now turn to the high-quality firm. If this firm sets a training level equal to $s_{h}^{f D}<s_{l}^{f}$, it earns profits equal to

$$
\pi_{h}^{D}\left(s_{h}^{D f}, s_{l}^{f}\right)=\frac{1.4962 \bar{\theta}^{2} s_{l}\left(2 s_{l}-0.2078 \bar{\theta}\right)^{2}\left(0.0416 \bar{\theta}-s_{l}\right)\left(s_{l}-0.0831 \bar{\theta}\right)^{2}}{\left(s_{l}-0.1662 \bar{\theta}\right)^{2}\left(16 s_{l}^{2}-2.7014 \bar{\theta} s_{l}+0.1105 \bar{\theta}^{2}\right)^{2}}-\frac{s_{l}^{2}}{2} .
$$

Expression (24) has one local maximum for $s_{h}^{D f}<s_{l}$, namely $s_{h}^{D f}=0.0208 \bar{\theta} \equiv \underline{s}_{h}^{D f}$. The deviation, however, is not profitable, in fact $\pi_{h}^{D}\left(\underline{s}_{h}^{D f}, s_{l}^{f}\right)=0.0006 \bar{\theta}^{2}<0.0073 \bar{\theta}^{2}=\pi_{h}\left(s_{h}^{f}, s_{l}^{f}\right)$. The total wages for the unions are obtained by direct substitution.

\section{B Proof of Lemma (3)}

To prove Lemma 3, we follow the steps of the preceding proof. The first-order conditions for the unions are the following. ${ }^{13}$

$$
\begin{aligned}
& \frac{\partial\left[E_{h}^{*}-C\left(s_{h}\right)\right]}{\partial s_{h}}=0 \quad \Leftrightarrow \quad\left(16 s_{h}-7 s_{l}\right) \rho \sigma=s_{h}, \\
& \frac{\partial\left[E_{l}^{*}-C\left(s_{l}\right)\right]}{\partial s_{l}}=0 \quad \Leftrightarrow \quad 4 s_{h}\left(5 s_{h}-2 s_{l}\right) \rho \tau=s_{l},
\end{aligned}
$$

where $\sigma \equiv\left(8192 s_{h}^{6}-25472 s_{h}^{5} s_{l}+35384 s_{h}^{4} s_{l}^{2}-26668 s_{h}^{3} s_{l}^{3}+11225 s_{h}^{2} s_{l}^{4}-2480 s_{h} s_{l}^{5}+224 s_{l}^{6}\right), \tau \equiv\left(2560 s_{h}^{5}+\right.$ $\left.-8152 s_{h}^{4} s_{l}+9276 s_{h}^{3} s_{l}^{2}-4981 s_{h}^{2} s_{l}^{3}+1294 s_{h} s_{l}^{4}-132 s_{l}^{5}\right)$ and $\rho \equiv \frac{4 \bar{\theta} s_{h}}{\left(4 s_{h}-s_{l}\right)^{2}\left(64 s_{h}^{2}-65 s_{h} s_{l}+16 s_{l}^{2}\right)^{3}}$.

Again, by allowing $s_{h}=\alpha s_{l}, \alpha>1$, and dividing (25) by (26) we obtain

$$
\frac{-4608 \alpha^{8}+23264 \alpha^{7}-49072 \alpha^{6}+60276 \alpha^{5}-46136 \alpha^{4}+22120 \alpha^{3}-6447 \alpha^{2}+1044 \alpha-72}{4608 \alpha^{7}-15072 \alpha^{6}+18864 \alpha^{5}-12020 \alpha^{4}+4176 \alpha^{3}-756 \alpha^{2}+56 \alpha}=0 .
$$

Equation (27) only has one root that is larger than one, namely $\alpha=3.0706$. Substitution back into (25) and (26) returns $s_{h}^{u}=0.0983 \bar{\theta}$ and $s_{l}^{u}=0.032 \bar{\theta}$.

As in the previous case, it remains to confirm the non-existence of profitable deviations for either union. We will begin with the low-skill union. If it leapfrogs the other union in the training level of its members, by setting $s_{l}^{D u}>s_{h}^{u}$, it obtains a total wage equal to

$$
E\left(u_{u}^{u}, s_{l}^{D u}\right)=\frac{1}{2}\left(s_{l}^{D u}\right)^{2}\left\{\frac{6 \bar{\theta}\left[0.6879 \bar{\theta}-16 s_{l}^{D u}\right]^{2}\left[-0.2948 \bar{\theta} s_{l}^{D u}+0.0097 \bar{\theta}^{2}+2\left(s_{l}^{D u}\right)^{2}\right]}{\left[4 s_{l}^{D u}-0.0983 \bar{\theta}\right]\left[-6.3873 \bar{\theta} s_{l}^{D u}+0.1545 \bar{\theta}^{2}+64\left(s_{l}^{D u}\right)^{2}\right]^{2}}-1\right\} .
$$

Expression (28) is negative for all $s_{l}^{D u}>s_{h}^{u}$ and $\bar{\theta}>0$, implying that there is no profitable leapfrogging for the low-skill union.

Let us now turn to the high-skill union. If it deviates to a utility level $s_{h}^{D u}<s_{l}^{u}$, the total wage is

$$
E_{h}\left(s_{h}^{D u}, s_{l}^{u}\right)=\frac{0.384 \bar{\theta}^{2} s_{h}^{D u}\left(0.16 \bar{\theta}-2 . s_{h}^{D u}\right)^{2}\left[0.002 \bar{\theta}^{2}-0.096 \bar{\theta} s_{h}^{D u}+\left(s_{h}^{D u}\right)^{2}\right]}{\left(0.128 \bar{\theta}-s_{h}^{D u}\right)\left[0.0655 \bar{\theta}^{2}-2.08 \bar{\theta} s_{h}^{D u}+16\left(s_{h}^{D u}\right)^{2}\right]^{2}}-\frac{\left(s_{h}^{D u}\right)^{2}}{2} .
$$

Expression (29) has a unique maximizer over $\left[0, s_{l}^{u}\right]$, namely $\underline{s}_{h}^{D u}=0.0177$, but it is easy to ascertain that $E_{h}\left(s_{h}^{u}, s_{l}^{u}\right)=0.0038 \bar{\theta}^{2}>0.0004 \bar{\theta}^{2}=E_{h}\left(\underline{s}_{h}^{D u}, s_{l}^{u}\right)$. The profits for the firms are obtained by direct substitution.

\section{Proof of Lemma 4}

(i) The objective functions of the agents are $E_{h}^{*}-C\left(s_{h}\right)$ and $\pi_{l}^{*}-C\left(s_{l}\right)$. The relevant first-order conditions are (25) and (21). We proceed as in the previous Lemmata, namely we set $s_{h}=\alpha s_{l}$, divide (25) by (21) and solve for $\alpha$. The unique solution larger than one is $\alpha=2.7787$, which yields $s_{l}^{u f}=0.0359 \bar{\theta}$ and $s_{h}^{u f}=0.0997 \bar{\theta}$. The candidate equilibrium total wage for the union is $E_{h}^{u f}=0.0036 \bar{\theta}^{2}$ and

\footnotetext{
${ }^{13}$ In this case as well, the second-order conditions are satisfied for all $s_{h}>s_{l}$ for firm $h$, whereas local concavity is ensured for union $l$.
} 
$\pi_{l}^{u f}=0.0001 \bar{\theta}^{2}$. It may be demonstrated that there are no profitable deviations for either agent. Second order conditions are fulfilled for all $s_{h}>s_{l}$. Direct substitution yields the profit for the high-quality firm and low-skill union.

(ii) The objective functions of the agents are $\pi_{h}^{*}-C\left(s_{h}\right)$ and $E_{l}^{*}-C\left(s_{l}\right)$. By setting $s_{h}=\alpha s_{l}$, dividing (20) by (26) and solving for $\alpha$ we obtain as unique solution larger than one $\alpha=4.1847$, which yields $s_{l}=0.0343 \bar{\theta}$ and $s_{h}=0.1437 \bar{\theta}$. The associated profits for the firm and union are, respectively, $0.0078 \bar{\theta}^{2}$ and $0.0006 \bar{\theta}$. As before, no profitable deviation exists for the firm or the union.

\section{Proof of Lemma 5}

The first-order conditions of problem (19) generate the system

$$
\left\{\begin{array}{l}
\frac{3 \bar{\theta} \Omega}{2\left(4 s_{h}-s_{l}\right)^{3}\left(-65 s_{h} s_{l}+64 s_{h}^{2}+16 s_{l}^{2}\right)^{3}}=s_{h}, \\
\frac{6 \bar{\theta} u_{h}^{2}\left(5 u_{h}-2 u_{l}\right) \Xi}{\left(4 u_{h}-u_{l}\right)^{3}\left(-65 u_{h} u_{l}+64 u_{h}^{2}+16 u_{l}^{2}\right)^{3}}=s_{l},
\end{array}\right.
$$

where $\Omega \equiv\left(-12939264 s_{h}^{8} s_{l}+21219712 s_{h}^{7} s_{l}^{2}-19358928 s_{h}^{6} s_{l}^{3}+10509900 s_{h}^{5} s_{l}^{4}-3285932 s_{h}^{4} s_{l}^{5}+454635 s_{h}^{3} s_{l}^{6}+\right.$ $\left.+36336 s_{h}^{2} s_{l}^{7}-20864 s_{h} s_{l}^{8}+3407872 s_{h}^{9}+2048 s_{l}^{9}\right)$ and $\Xi \equiv\left(-341360 u_{h}^{5} u_{l}+434164 u_{h}^{4} u_{l}^{2}-291126 u_{h}^{3} u_{l}^{3}+\right.$ $\left.+109061 u_{h}^{2} u_{l}^{4}-21694 u_{h} u_{l}^{5}+109568 u_{h}^{6}+1792 u_{l}^{6}\right)$.

By setting $s_{h}=\alpha s_{l}$ and dividing the first equation by the second we obtain $\frac{-2191360 \alpha^{10}+11111616 \alpha^{9}-24353424 \alpha^{8}+30515544 \alpha^{7}-23869156 \alpha^{6}+11816268 \alpha^{5}-3495324 \alpha^{4}+468971 \alpha^{3}+36336 \alpha^{2}-20864 \alpha+2048}{2191360 \alpha^{9}-7703744 \alpha^{8}+11414160 \alpha^{7}-9295832 \alpha^{6}+4510228 \alpha^{5}-1306368 \alpha^{4}+209392 \alpha^{3}-14336 \alpha^{2}}=0$.

The only solution to (31) that is both real and greater than one is $\alpha=1.471$. By following the same procedure as above, we obtain the welfare-maximizing training levels $s_{h}^{W}=0.3056 \bar{\theta}$ and $s_{l}^{W}=0.2077 \bar{\theta}$. It remains to confirm the concavity of the objective function $W(\cdot)$ with respect to $s_{h}$ and $s_{l}$. The Hessian matrix of the problem is

$$
H=\left(\begin{array}{cc}
\eta s_{l}^{2}-1 & -\eta s_{h} s_{l} \\
-\eta s_{h} s_{l} & \eta s_{h}^{2}-1
\end{array}\right),
$$

where $\eta \equiv \frac{12 \bar{\theta}}{\left(4 s_{h}-s_{l}\right)^{4}\left(64 s_{h}^{2}-65 s_{h} s_{l}+16 s_{l}^{2}\right)^{4}}\left(-105511104 s_{h}^{8} s_{l}+230432448 s_{h}^{7} s_{l}^{2}-282164040 s_{h}^{6} s_{l}^{3}+217800999 s_{h}^{5} s_{l}^{4}+\right.$ $\left.-110985765 s_{h}^{4} s_{l}^{5}+37515072 s_{h}^{3} s_{l}^{6}-8128512 s_{h}^{2} s_{l}^{7}+1025184 s_{h} s_{l}^{8}+19730432 s_{h}^{9}-57344 s_{l}^{9}\right)$.

It is a matter of calculations to demonstrate that (32) is negative definite at $\left(s_{h}^{W}, s_{l}^{W}\right)$, and its first order leading principal minor at $\left(s_{h}^{W}, s_{l}^{W}\right)$ is -1.49 and the second order leading principal minor is 1.4712 . 


\section{E Asymmetric bargaining}

The following tables report the equilibrium values of qualities, prices, demands, profit, total and individual wage and welfare under asymmetric bargaining.

\begin{tabular}{c|c|c|c|c|c} 
& $f$ & $u$ & $f u$ & $u f$ & Soc. Op. \\
\hline$s_{h}, s_{l}$ & $0.0671 \bar{\theta}, 0.028 \bar{\theta}$ & $0.1404 \bar{\theta}, 0.0698 \bar{\theta}$ & No eq. & $0.1268 \bar{\theta}, 0.0327 \bar{\theta}$ & $0.2583 \bar{\theta}, 0.242 \bar{\theta}$ \\
$p_{h}, p_{l}$ & $0.0396 \bar{\theta}^{2}, 0.0127 \bar{\theta}^{2}$ & $0.0769 \bar{\theta}^{2}, 0.0294 \bar{\theta}^{2}$ & - & $0.0839 \bar{\theta}^{2}, 0.0164 \bar{\theta}^{2}$ & $0,0316 \bar{\theta}^{2}, 0.0197 \bar{\theta}^{2}$ \\
$D_{h}, D_{l}$ & $0.3106,0.2378$ & $0.3272,0.2516$ & - & $0.2831,0.2149$ & $0.5114,0.4071$ \\
$\pi_{h}, \pi_{l}$ & $0.0015 \bar{\theta}^{2}, 0.0005 \bar{\theta}^{2}$ & $0.0075 \bar{\theta}^{2}, 0.0022 \bar{\theta}^{2}$ & - & $0.0075 \bar{\theta}^{2}, 0.0006 \bar{\theta}^{2}$ & $0.0035 \bar{\theta}^{2}, 0.002 \bar{\theta}^{2}$ \\
$E_{h}, E_{l}$ & $0.0085 \bar{\theta}^{2}, 0.0021 \bar{\theta}^{2}$ & $0.0077 \bar{\theta}^{2}, 0.027 \bar{\theta}^{2}$ & - & $0.081 \bar{\theta}^{2}, 0.0024 \bar{\theta}^{2}$ & $0.01 \bar{\theta}^{2}, 0.006 \bar{\theta}^{2}$ \\
$w, r$ & $0.0274 \bar{\theta}^{2}, 0.0088 \bar{\theta}^{2}$ & $0.0538 \bar{\theta}^{2}, 0.0206 \bar{\theta}^{2}$ & - & $0.0572 \bar{\theta}^{2}, 0.0112 \bar{\theta}^{2}$ & $0.0196 \bar{\theta}^{2}, 0.0148 \bar{\theta}^{2}$ \\
$W$ & $0.02907 \bar{\theta}^{2}$ & $0.03552 \bar{\theta}^{2}$ & - & $0.03221 \bar{\theta}^{2}$ & $0.06477 \bar{\theta}^{2}$
\end{tabular}

Table 1: All bargaining power to workers (monopoly union).

\begin{tabular}{c|c|c|c|c|c} 
& $f$ & $u$ & $f u$ & $u f$ & Soc. Op. \\
\hline$s_{h}, s_{l}$ & $0.1025 \bar{\theta}, 0.0353 \bar{\theta}$ & $0.1261 \bar{\theta}, 0.0506 \bar{\theta}$ & No Eq. & $0.1213 \bar{\theta}, 0.0373 \bar{\theta}$ & $0.2723 \bar{\theta}, 0.2353 \bar{\theta}$ \\
$p_{h}, p_{l}$ & $0.0565 \bar{\theta}^{2}, 0.0136 \bar{\theta}^{2}$ & $0.066 \bar{\theta}^{2}, 0.0185 \bar{\theta}^{2}$ & - & $0.0689 \bar{\theta}^{2}, 0.0148 \bar{\theta}^{2}$ & $0,0494 \bar{\theta}^{2}, 0.031 \bar{\theta}^{2}$ \\
$D_{h}, D_{l}$ & $0.3617,0.2529$ & $0.3719,0.2609$ & - & $0.3554,0.248$ & $0.528,0.3653$ \\
$\pi_{h}, \pi_{l}$ & $0.0035 \bar{\theta}^{2}, 0.0008 \bar{\theta}^{2}$ & $0.0104 \bar{\theta}^{2}, 0.002 \bar{\theta}^{2}$ & - & $0.0106 \bar{\theta}^{2}, 0.0008 \bar{\theta}^{2}$ & $0.0093 \bar{\theta}^{2}, 0.0042 \bar{\theta}^{2}$ \\
$E_{h}, E_{l}$ & $0.0116 \bar{\theta}^{2}, 0.002 \bar{\theta}^{2}$ & $0.0061 \bar{\theta}^{2}, 0.015 \bar{\theta}^{2}$ & - & $0.065 \bar{\theta}^{2}, 0.0021 \bar{\theta}^{2}$ & $0.0154 \bar{\theta}^{2}, 0.0071 \bar{\theta}^{2}$ \\
$w, r$ & $0.0322 \bar{\theta}^{2}, 0.0078$ & $0.0379 \bar{\theta}^{2}, 0.0107$ & - & $0.0391 \bar{\theta}^{2}, 0.0084 \bar{\theta}^{2}$ & $0.0308 \bar{\theta}^{2}, 0.0193 \bar{\theta}^{2}$ \\
$W$ & $0.0188 \bar{\theta}^{2}$ & $0.0357 \bar{\theta}^{2}$ & - & $0.0265 \bar{\theta}^{2}$ & $0.0633 \bar{\theta}^{2}$
\end{tabular}

Table 2: $75 \%$ of bargaining power to workers, $25 \%$ to firms.

\begin{tabular}{c|c|c|c|c|c} 
& $f$ & $u$ & $f u$ & $u f$ & Soc. Op. \\
\hline$s_{h}, s_{l}$ & $0.1955 \bar{\theta}, 0.046 \bar{\theta}$ & $0.0563 \bar{\theta}, 0.0148 \bar{\theta}$ & $0.1919 \bar{\theta}, 0.0168 \bar{\theta}$ & No Eq. & $0.3447 \bar{\theta}, 0.1726 \bar{\theta}$ \\
$p_{h}, p_{l}$ & $0.0915 \bar{\theta}^{2}, 0.0122 \bar{\theta}^{2}$ & $0.0257 \bar{\theta}^{2}, 0.0038 \bar{\theta}^{2}$ & $0.1015 \bar{\theta}^{2}, 0.005 \bar{\theta}^{2}$ & - & $0.1175 \bar{\theta}^{2}, 0.0336 \bar{\theta}$ \\
$D_{h}, D_{l}$ & $0.4693,0.2657$ & $0.4733,0.2681$ & $0.87,0.253$ & - & $0.5123,0.2928$ \\
$\pi_{h}, \pi_{l}$ & $0.0138 \bar{\theta}^{2}, 0.0014 \bar{\theta}^{2}$ & $0.0093 \bar{\theta}^{2}, 0.008 \bar{\theta}^{2}$ & $0.0168 \bar{\theta}^{2}, 0.001 \bar{\theta}^{2}$ & - & $0.0452 \bar{\theta}^{2}, 0.0074 \bar{\theta}^{2}$ \\
$E_{h}, E_{l}$ & $0.01 \bar{\theta}^{2}, 0.0007 \bar{\theta}^{2}$ & $0.0013 \bar{\theta}, 0.0001 \bar{\theta}^{2}$ & $0.0103 \bar{\theta}^{2}, 0.0001 \bar{\theta}^{2}$ & - & $0.015 \bar{\theta}^{2}, 0.0025 \bar{\theta}^{2}$ \\
$w, r$ & $0.0214 \bar{\theta}^{2}, 0.003 \bar{\theta}^{2}$ & $0.006 \bar{\theta}^{2}, 0.0009 \bar{\theta}^{2}$ & $0.023 \bar{\theta}^{2}, 0.0011 \bar{\theta}^{2}$ & - & $0.0294 \bar{\theta}^{2}, 0.0084 \bar{\theta}^{2}$ \\
$W$ & $0.0549 \bar{\theta}^{2}$ & $0.0232 \bar{\theta}^{2}$ & $0.05 \bar{\theta}^{2}$ & - & $0.0743 \bar{\theta}^{2}$
\end{tabular}

Table 3: $25 \%$ of bargaining power to workers, $75 \%$ to firms.

\begin{tabular}{c|c|c|c|c|c} 
& $f$ & $u$ & $f u$ & $u f$ & Soc. Op. \\
\hline$s_{h}, s_{l}$ & $0.2533 \bar{\theta}, 0.04824 \bar{\theta}$ & No Eq. & No Eq. & No Eq. & $0.378 \bar{\theta}, 0.1428 \bar{\theta}$ \\
$p_{h}, p_{l}$ & $0.3435 \bar{\theta}, 0.1718 \bar{\theta}$ & - & - & - & $0.1298 \bar{\theta}^{2}, 0.0245 \bar{\theta}^{2}$ \\
$D_{h}, D_{l}$ & $0.525,0.0625$ & - & - & - & $0.5521,0.2761$ \\
$\pi_{h}, \pi_{l}$ & $0.02444 \bar{\theta}^{2}, 0.0015 \bar{\theta}^{2}$ & - & - & - & $0.0717 \bar{\theta}^{2}, 0.0068 \bar{\theta}^{2}$ \\
$E_{h}, E_{l}$ & 0,0 & - & - & - & 0,0 \\
$w, r$ & 0,0 & - & - & - & 0,0 \\
$W$ & $0.0692 \bar{\theta}^{2}$ & - & - & - & $0.0817 \bar{\theta}^{2}$
\end{tabular}

Table 4: All bargaining power to firms (see Motta, 1993). 


\section{References}

Acemoglu, D. (1997). "Training and innovation in an imperfect labour market". Review of Economic Studies, 64(3):445-64.

Acemoglu, D. and Pischke, J. (1999a). "The structure of wages and investment in general training". Journal of Political Economy, 107(3): 539-572.

Acemoglu, D. and Pischke, J.-S. (1998). "Why do firms train? theory and evidence". The Quarterly Journal of Economics, 113(1): 79-119.

Acemoglu, D. and Pischke, J.-S. (1999b). "Beyond becker: Training in imperfect labour markets". The Economic Journal, 109(453): F112-F142.

Aidt, T. S. and Sena, V. (2005). "Unions: Rent creators or extractors?" Scandinavian Journal of Economics, $107(1): 103-121$.

Bacchiega, E. (2007). "Wage bargaining and vertical differentiation". International Review of Economics, 54(1):35-52.

Boccard, N. and Wauthy, X. (2010). "Equilibrium vertical differentiation in a Bertrand model with capacity precommitment". International Journal of Industrial Organization, 28(3):288 - 297.

Booth, A. L. and Chatterji, M. (1998). "Unions and efficient training". The Economic Journal, 108(447):pp. 328-343.

Booth, A. L. and Snower, D. J. (1995). "Introduction: Does the free market produce enough skills?" In "Acquiring Skills: Market Failures, their Symptoms and Policy Responses", pages 1-18. Cambridge: Cambridge University Press.

Card, D. (1996). "The effect of unions on the structure of wages: A longitudinal analysis". Econometrica, 64(4): 957-979.

Courakis, A. S. (1991). "Labour skills and human capital in the explanation of trade patterns". Oxford Economic Papers, 43(3):pp. 443-462.

Freeman, R. B. (1980). "Unionism and the dispersion of wages". NBER Working Papers 0248, National Bureau of Economic Research, Inc.

Freeman, R. B. (1984). "Longitudinal analyses of the effects of trade unions". Journal of Labor Economics, 2(1): $1-26$.

Freeman, R. B. (1991). "How much has de-unionisation contributed to the rise in male earnings inequality?" Working Paper 3826, National Bureau of Economic Research.

Freeman, R. B. and Medoff, J. L. (1979). "The two faces of unionism". Public Interest, 57:69-93.

Gabszewicz, J. J. and Turrini, A. (1999). "Workers' skills and product selection". Revue Économique, $\mathbf{5 0}(3): 383-391$.

Gabszewicz, J. J. and Turrini, A. (2000). "Workers' skills, product quality and industry equilibrium". International journal of industrial organization, 18(4):575-593.

Goeddeke, A. K. (2010). "Unionized Oligopolies - A Survey". SSRN eLibrary.

Gosling, A. and Machin, S. (1994). "Trade unions and the dispersion of earnings in british establishments, 1980-90". Working Paper 4732, National Bureau of Economic Research.

Greenaway, D. and Torstensson, J. (2000). "Economic geography, comparative advantage and trade within industries: Evidence from the OECD". Journal of Economic Integration, 15(2):260-280.

Hashimoto, M. (1981). "Firm-specific human capital as a shared investment". The American Economic Review, 71(3): 475-482.

Leuven, E. (2005). "The economics of private sector training: A survey of the literature". Journal of Economic Surveys, 19(1):91-111.

MacLeod, W. and Malcomson, J. (1993). "Investment, holdup and the form of market contracts". American Economic Review, 37:811-817. 
Martín-Montaner, J. and Ríos, V. (2002). "Vertical specialization and intra-industry trade: The role of factor endowments". Review of World Economics, 138:340-365.

Maskus, K., Sveikauskas, C., and Webster, A. (1994). "The composition of the human capital stock and its relation to international trade: Evidence from the US and Britain". Review of World Economics, 130:50-76.

McDonald, I. M. and Solow, R. M. (1981). "Wage bargaining and employment". The American Economic Review, 71(5): 896-908.

Motta, M. (1993). "Endogenous quality choice: Price vs. quantity competition". The Journal of Industrial Economics, 41(2): 113-131.

Mussa, M. and Rosen, S. (1978). "Monopoly and product quality". Journal of Economic Theory, 18(2):301317.

Naylor, R. (1998). "International trade and economic integration when labour markets are generally unionised". European Economic Review, 42(7):1251-1267.

Naylor, R. (1999). "Union wage strategies and international trade". The Economic Journal, 109(452):102125.

Naylor, R. (2000). "Trade and wages when the trade regime is determined endogenously". Review of International Economics, 8(3):556-565.

Nickell, S. J. and Andrews, M. (1983). "Unions, real wages and employment in Britain 1951-79". Oxford Economic Papers, 35:pp. 183-206.

OECD (2011). "Towards an OECD skills strategy".

Oosterbeek, H., Sloof, R., and Sonnemans, J. (2007). "Who should invest in specific training?" Journal of Population Economics, 20:329-357.

Oulton, N. (1996). "Work force skills and export competitiveness". In A. L. Booth and D. Snower, editors, "Acquiring Skills", Cambridge University Press.

Rigby, M. (2002). "Spanish trade unions and the provision of continuous training: Partnership at a distance". Employee Relations, 24(5):500-515.

Schott, P. K. (2004). "Across-product versus within-product specialization in international trade". The Quarterly Journal of Economics, 119(2):647-678.

Shintoyo, N. (2010). "Worker-financed versus firm-sponsored training: How are skilled workers supplied to the economy?" Economica, 77(305):110-127.

Sørensen, J. R. (1992). "Profit-sharing in a unionized Cournot duopoly". Journal of Economics, 55:151-167.

Stevens, M. (1994). "A theoretical model of on-the-job training with imperfect competition". Oxford Economic Papers, 46(4):537-562.

Sutherland, J. and Rainbird, H. (2000). "Unions and workplace learning: conflict or cooperation with the employer?" In H. Rainbird, editor, "Training in the Workplace", pages 189-209. Macmillan Press.

Takahashi, B. and Meléndez, E. (2004). "Union-sopnsored workforce development initiatives". In E. Meléndez, editor, "Communities and Workforce Development", chapter 4, pages 119-150. W.E. Upjohn Institute.

Webster, A. (1993). "The skill and higher educational content of UK net exports". Oxford Bulletin of Economics and Statistics, 55(2):141-169. 


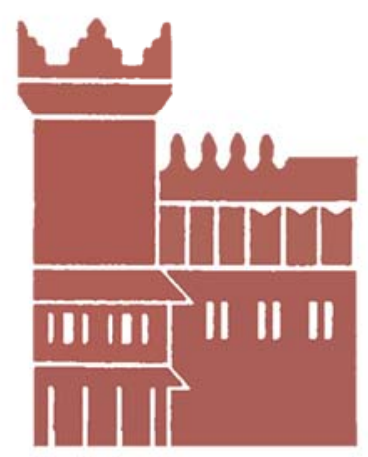

Alma Mater Studiorum - Università di Bologna DEPARTMENT OF ECONOMICS

Strada Maggiore 45

40125 Bologna - Italy

Tel. +39051 2092604

Fax +390512092664

http://www.dse.unibo.it 